\title{
Analysis of Social Cohesion in Health Data by Factor Analysis Method: The Ghanaian Perspective
}

\author{
Bashiru I. I. Saeed ${ }^{1,2}$, Zhao Xicang ${ }^{1}$, A. A. I. Musah ${ }^{3}$, A. R. Abdul-Aziz ${ }^{2}$ Alfred Yawson ${ }^{4} \&$ Azumah Karim $^{5}$ \\ ${ }^{1}$ School of Finance and Economics, Jiangsu University, Jiangsu, China \\ ${ }^{2}$ Mathematics and Statistics Department, Kumasi Polytechnic, Kumasi, Ghana \\ ${ }^{3}$ Mathematics and Statistics Department, Tamale Polytechnic, Tamale, Ghana \\ ${ }^{4}$ Department of Community Health, University of Ghana Medical School, College of Health Sciences, Korle-Bu, \\ Accra, Ghana. \\ ${ }^{5}$ Mathematics and Statistics Department, KNUST, Kumasi, Ghana \\ Correspondence: Zhao Xicang, Jiangsu University, 301 Xuefu Road, Zhenjiang, Jiangsu, China. Tel: \\ 86-139-5281-9177. E-mail: zxc@ujs.edu.cn
}

Received: August 21, $2013 \quad$ Accepted: September 23, $2013 \quad$ Online Published: November 18, 2013
doi:10.5539/jel.v2n4p177
URL: http://dx.doi.org/10.5539/jel.v2n4p177

\begin{abstract}
We investigated the study of the overall social cohesion of Ghanaians. In this study, we considered the paramount interest of the involvement of Ghanaians in their communities, their views of other people and institutions, and their level of interest in both local and national politics. The factor analysis method was employed for analysis using R software. The incontrovertible evidence from the results showed the factors that were measured to enhance and promote social cohesion among Ghanaians were community, political, neighborliness, socio-cultural, confidence and security. Our results perfectectly fit our expectation in terms of knowledge in our socio-political arena.
\end{abstract}

Keywords: social cohesion, community, health data, factor analysis method, Ghana

\section{Introduction}

The term social cohesion has been increasingly invoked amongst policy-makers, both nationally and internationally, since the late 1980s. Its frequent usage reflects widespread and diverse concerns about the effects of social change on the social fabric - not least those that may arise from the increasing inequality and social diversity that accompanies globalization. With the 2008 financial crisis and subsequent global recession comes mounting unemployment, and such concerns are now necessarily intensified. At the same time the concept of social cohesion has seen a revival in social theory (Chan, To \& Chan, 2006; Green, Preston \& Janmaat, 2006; Osberg, 2003).

Other revered researchers have established positive (Marschall \& Stolle 2004), or insignificant (Aizlewood \& Pendakur 2005; Leigh 2006; Soroka, Johnston \& Banting, 2007; Sturgis \& Allum 2001) diversity effects on absolute trust, much more lot of studies have established notably important inverse association between diversity and measures of social cohesion (Becares, Stafford, Laurence, \& Nazroo, 2011; Fieldhouse \& Cutts 2010; Letki 2008; Pennant 2005; Putnam 2007), albeit that the magnitude of the underlying effects has been trivial in some cases, particularly in comparison to measures of socio-economic disadvantage (Letki, 2008; Sturgis, Brunton-Smith, Read, \& Allum, 2011; Taylor, Twigg, \& Mohan, 2010). And, although, the magnitude of the relationship appears to vary across ethnic groups, the basic patterns of negative association between diversity and social capital is broadly consistent across North America and the European contexts in which it has been examined (Fieldhouse \& Cutts, 2010; Lancee \& Dronkers, 2011).

Paul, Marie \& Monique (2010) argued that the existence of the multifaceted constructs of social cohesion suggested by theory has been corroborated by empirical analysis of the EVS data (i.e., Social cohesion consists of components of formal and substantial relationships and political and social-cultural domains). Cassiers \& Kesteloot (2012) addressed the increasing social-spatial inequalities in European cities and their impact on the possibilities for fostering social cohesion. Hickman, Crowley \& Mai (2008) observed in their book that social 
cohesion is achieved through people (new arrivals as well as the long-term settled) being able to resolve the conflicts and tensions within their day-to-day lives in ways that they find positive and viable. Andrews (2011) suggested that mainline Protestant communities enhance social cohesion in rural England, while Evangelical communities do not. Meanwhile, rural dwellers are significantly less likely than residents of urban areas to report their health as being fair or poor and to report common mental disorders, independent of their social-demographic characteristics (Riva, Curtis, Gauvin \& Fagg, 2009).

A useful model of social capital recognizes two components, structural and cognitive (Harpham, Grant \& Thomas, 2002). The cognitive component, labeled 'social cohesion', is conceptualized as a collective community level characteristic measured by the levels of trust, norms of reciprocity and the formation of strong social bonds within the local social structure (Kawachi \& Berkman, 2000; Subramanian, Lochner \& Kawachi, 2003; Stafford, Bartley, Sacker \& Marmot, 2003). There is some evidence to suggest that this concept of community-level social cohesion is useful in investigating the determinants of general health status (Stafford, Bartley, Sacker \& Marmot, 2003; Subramanian, Kim \& Kawachi, 2002).

There have been many attempts to conceptualize and measure social cohesion. Different definitions and approaches have yielded different types of indicators and empirical results. However, most of these attempts will only partially cover the complex, multilevel and multidimensional nature of the concept. Since the measurement of social cohesion describes the nature of a certain group or society, the indicators of social cohesion generated have great potential to be used in comparative research. So to identify question items relating to the concept of cognitive social cohesion we used factor analysis with principal components analysis followed by a varimax rotation to identify a set of underlying common factors. To this end, this article seeks to examine the correlation among community, social and political issues relative to individual's response to a variety of health questions.

\section{Method}

To achieve the stated objectives of the study, a survey data on Global Ageing and Adult Health in Ghana was employed. The survey was conducted in Ghana by SAGE under the initiative of the World Health Organization (WHO) in the year 2007. The survey which involved a total of 6000 households employed both stratified and systematic random sampling techniques. That is, the entire country was first stratified by regions and the respondents who were eighteen (18) years and above in each household were randomly interviewed using a systematic approach.

The data set contains information on self-reported health status, demographic and socioeconomic characteristics as well as social cohesion. The variables considered in the study include attending public meeting, meeting community leader (meet leader), organizational meeting (club), work with neighbors (neighborhood), invite friends home (friends), visit friends (in other homes), socialize with other (coworkers), religious services, attending social meetings (how often go out?), satisfy with going out (want to get out more?), reasons for not getting out (why not?), general trust, have someone to trust, neighbors, coworkers, strangers, safe at home, safe on the street, a victim, interest, voted, say in government, and express yourself freely.

\subsection{Model Specification}

The primary variable of interest was the overall social cohesion of Ghanaians. It is interdependent in nature with three factors namely; Community, Social and Political aspects of the individual's life.

The factor analysis method was therefore the appropriate model for the analysis. The paramount interest of the involvement of Ghanaians in their communities, their views on other people and institutions and their level of interest in both local and national politics were considered.

Table 1. Descriptive statistics

\begin{tabular}{llll}
\hline & Mean & Std. Deviation & Analysis N \\
\hline q6001: public meeting & 1.62 & 1.014 & 585 \\
q6002: meet leader & 2.00 & 1.266 & 585 \\
q6003: club & 1.94 & 1.243 & 585 \\
q6004: neighborhood & 1.67 & 1.181 & 585 \\
q6005: friends & 3.38 & 1.431 & 585 \\
q6006: in another home & 2.61 & 1.430 & 585
\end{tabular}




\begin{tabular}{llll} 
q6007: coworkers & 1.94 & 1.409 & 585 \\
q6008: religious services & 3.02 & 1.404 & 585 \\
q6009: how often go out? & 2.57 & 1.303 & 585 \\
q6010: want to get out more? & 1.18 & 1.119 & 585 \\
q6011: why not? & 2.21 & 2.288 & 585 \\
q6012: general trust & 1.48 & .781 & 585 \\
q6013: have someone to trust & 1.37 & .977 & 585 \\
q6014: neighbors & 2.81 & 1.193 & 585 \\
q6015: coworkers & 3.04 & 1.226 & 585 \\
q6016: strangers & 3.66 & 1.229 & 585 \\
q6017: safe at home & 1.94 & .970 & 585 \\
q6018: safe on street & 2.43 & 1.308 & 585 \\
q6019: victim & 1.99 & .541 & 585 \\
q6020: interest & 2.83 & 1.290 & 585 \\
q6021: voted & 1.28 & .920 & 585 \\
q6022: say in govt & 3.63 & 1.395 & 585 \\
q6023: express yourself freely & 2.67 & 1.316 & 585 \\
\hline
\end{tabular}

Table 2. Correlation matrix

\begin{tabular}{|c|c|c|c|c|c|c|c|c|c|c|c|c|}
\hline & q6001 & $\mathrm{q} 6002$ & q6003 & q6004 & $\mathrm{q} 6005$ & q6006 & $\mathrm{q} 6007$ & q6008 & q6009 & $\mathrm{q} 6010$ & q6011 & q6012 \\
\hline q6001 & 1.000 & .648 & .566 & .686 & .227 & .406 & .548 & .384 & .414 & .389 & .280 & .199 \\
\hline q6002 & .648 & 1.000 & .522 & .568 & .313 & .345 & .404 & .358 & .414 & .330 & .140 & .156 \\
\hline q6003 & .566 & .522 & 1.000 & .588 & .249 & .418 & .461 & .431 & .445 & .362 & .199 & .192 \\
\hline q6004 & .686 & .568 & .588 & 1.000 & .224 & .385 & .566 & .370 & .355 & .336 & .234 & .168 \\
\hline q6005 & .227 & .313 & .249 & .224 & 1.000 & .509 & .287 & .284 & .307 & .195 & .233 & .041 \\
\hline q6006 & .406 & .345 & .418 & .385 & .509 & 1.000 & .565 & .475 & .432 & .276 & .409 & .122 \\
\hline q6007 & .548 & .404 & .461 & .566 & .287 & .565 & 1.000 & .370 & .326 & .289 & .344 & .143 \\
\hline q6008 & .384 & .358 & .431 & .370 & .284 & .475 & .370 & 1.000 & .449 & .241 & .312 & .098 \\
\hline q6009 & .414 & .414 & .445 & .355 & .307 & .432 & .326 & .449 & 1.000 & .275 & .142 & .140 \\
\hline q6010 & .389 & .330 & .362 & .336 & .195 & .276 & .289 & .241 & .275 & 1.000 & .359 & .297 \\
\hline q6011 & .280 & .140 & .199 & .234 & .233 & .409 & .344 & .312 & .142 & .359 & 1.000 & .094 \\
\hline q6012 & .199 & .156 & .192 & .168 & .041 & .122 & .143 & .098 & .140 & .297 & .094 & 1.000 \\
\hline q6013 & .195 & .143 & .139 & .175 & .068 & .120 & .150 & .095 & .166 & .345 & .060 & .433 \\
\hline q6014 & .088 & .040 & .100 & .051 & -.089 & .043 & .076 & .062 & .091 & .108 & .071 & .407 \\
\hline q6015 & .137 & .005 & .117 & .077 & .044 & .189 & .132 & .147 & .003 & .127 & .264 & .323 \\
\hline q6016 & .049 & -.073 & .031 & .013 & .095 & .147 & .060 & .089 & .039 & .151 & .310 & .262 \\
\hline q6017 & .238 & .087 & .227 & .223 & .058 & .158 & .188 & .143 & .111 & .224 & .066 & .339 \\
\hline q6018 & .110 & .037 & .142 & .107 & .000 & -.019 & .022 & .050 & .021 & .155 & -.022 & .168 \\
\hline q6019 & .362 & .262 & .269 & .298 & .208 & .230 & .262 & .208 & .228 & .338 & .200 & .500 \\
\hline q6020 & .033 & .030 & .081 & .014 & .112 & .007 & -.096 & .053 & .112 & .162 & -.085 & .163 \\
\hline q6021 & .344 & .198 & .228 & .318 & .119 & .196 & .205 & .133 & .167 & .337 & .163 & .322 \\
\hline q6022 & -.010 & -.027 & -.012 & -.042 & .094 & -.019 & -.087 & .035 & -.048 & .118 & .037 & .133 \\
\hline q6023 & .165 & .144 & .137 & .121 & .081 & .027 & .051 & .089 & .044 & .162 & -.004 & .210 \\
\hline
\end{tabular}


The size of the factor loadings (correlation coefficients between the variables and the factors they represent) will help in the interpretation. As a general rule, variables with large loadings indicate that they are representative of the factor, while small loadings suggest they are not. The rule of thumb suggests that factor loadings greater than \pm 0.33 are considered to meet the nominal level of practical significance. The reason being that when \pm 0.33 is squared, it represents the amount of the variables total variance accounted for by the factor. The factor loading of 0.33 denotes that approximately $10 \%$ of the variable's total variance is accounted for by the factor.

Examining the Correlation Matrix (see Table 2) revealed fairly high correlations among q6001, q6002, q6003, q6004, q6006, q6007, q6008, q6010, q6009, q6011 and q6012 (community involvement variables) were greater than 0.33 .

Table 3. Correlation matrix continuous

\begin{tabular}{llllllllllll}
\hline & $\mathrm{q} 6013$ & $\mathrm{q} 6014$ & $\mathrm{q} 6015$ & $\mathrm{q} 6016$ & $\mathrm{q} 6017$ & $\mathrm{q} 6018$ & $\mathrm{q} 6019$ & $\mathrm{q} 6020$ & $\mathrm{q} 6021$ & $\mathrm{q} 6022$ & $\mathrm{q} 6023$ \\
\hline $\mathrm{q} 6001$ & .195 & .088 & .137 & .049 & .238 & .110 &. $\mathbf{3 6 2}$ & .033 & $\mathbf{. 3 4 4}$ & -.010 & .165 \\
$\mathrm{q} 6002$ & .143 & .040 & .005 &. .073 & .087 & .037 & .262 & .030 & .198 & -.027 & .144 \\
$\mathrm{q} 6003$ & .139 & .100 & .117 & .031 & .227 & .142 & .269 & .081 & .228 & -.012 & .137 \\
$\mathrm{q} 6004$ & .175 & .051 & .077 & .013 & .223 & .107 & .298 & .014 & .318 & -.042 & .121 \\
$\mathrm{q} 6005$ & .068 & -.089 & .044 & .095 & .058 & .000 & .208 & .112 & .119 & .094 & .081 \\
$\mathrm{q} 6006$ & .120 & .043 & .189 & .147 & .158 & -.019 & .230 & .007 & .196 & -.019 & .027 \\
$\mathrm{q} 6007$ & .150 & .076 & .132 & .060 & .188 & .022 & .262 & -.096 & .205 & -.087 & .051 \\
$\mathrm{q} 6008$ & .095 & .062 & .147 & .089 & .143 & .050 & .208 & .053 & .133 & .035 & .089 \\
$\mathrm{q} 6009$ & .166 & .091 & .003 & .039 & .111 & .021 & .228 & .112 & .167 & -.048 & .044 \\
$\mathrm{q} 6010$ &. $\mathbf{3 4 5}$ & .108 & .127 & .151 & .224 & .155 & $\mathbf{. 3 3 8}$ & .162 & $\mathbf{. 3 3 7}$ & .118 & .162 \\
$\mathrm{q} 6011$ & .060 & .071 & .264 & .310 & .066 & -.022 & .200 & -.085 & .163 & .037 & -.004 \\
$\mathrm{q} 6012$ &. $\mathbf{4 3 3}$ &. $\mathbf{. 4 0 7}$ & .323 & .262 &. $\mathbf{3 3 9}$ & .168 & $\mathbf{. 5 0 0}$ & .163 & .322 & .133 & .210 \\
$\mathrm{q} 6013$ & 1.000 & .190 & .131 & .111 & .216 & .194 & $\mathbf{. 3 7 6}$ & .160 & .300 & .091 & .131 \\
$\mathrm{q} 6014$ & .190 & 1.000 &. $\mathbf{6 4 5}$ &. $\mathbf{4 4 0}$ & .303 & .315 & .213 & .203 & .177 & .097 & .076 \\
$\mathrm{q} 6015$ & .131 &. $\mathbf{6 4 5}$ & 1.000 & $\mathbf{. 5 7 5}$ & .227 & .279 & .256 & .117 & .208 & .216 & .156 \\
$\mathrm{q} 6016$ & .111 &. $\mathbf{4 4 0}$ & $\mathbf{. 5 7 5}$ & 1.000 & .112 & .140 & .234 & .064 & .183 & .255 & .006 \\
$\mathrm{q} 6017$ & .216 & .303 & .227 & .112 & 1.000 & $\mathbf{. 5 5 1}$ & .323 & .262 & .321 & .077 & .229 \\
$\mathrm{q} 6018$ & .194 & .315 & .279 & .140 &. $\mathbf{5 5 1}$ & 1.000 & .201 & .300 & .269 & .224 & .230 \\
$\mathrm{q} 6019$ & $\mathbf{. 3 7 6}$ & .213 & .256 & .234 & .323 & .201 & 1.000 & .197 & $\mathbf{. 4 1 9}$ & .217 & .224 \\
$\mathrm{q} 6020$ & .160 & .203 & .117 & .064 & .262 & .300 & .197 & 1.000 & $\mathbf{. 5 4 1}$ & $\mathbf{. 4 8 9}$ & $\mathbf{. 5 4 9}$ \\
$\mathrm{q} 6021$ & .300 & .177 & .208 & .183 & .321 & .269 & $\mathbf{. 4 1 9}$ & $\mathbf{. 5 4 1}$ & 1.000 & $\mathbf{. 3 9 6}$ & $\mathbf{. 5 2 1}$ \\
$\mathrm{q} 6022$ & .091 & .097 & .216 & .255 & .077 & .224 & .217 &. $\mathbf{4 8 9}$ & $\mathbf{. 3 9 6}$ & 1.000 & $\mathbf{. 5 2 8}$ \\
$\mathrm{q} 6023$ & .131 & .076 & .156 & .006 & .229 & .230 & .224 & $\mathbf{. 5 4 9}$ & $\mathbf{. 5 2 1}$ & $\mathbf{. 5 2 8}$ & 1.000 \\
\hline
\end{tabular}

From Correlation Table Continuous (Table 3) fair high correlation among q6013, q6014, q6015, q6016, q6017, q6018 and q6019 (social involvement indicators), indicated a correlation greater than 0.33. Similarly, q6019, q6020, q6021, q6022 and q6023 (political variables) reported correlation more than 0.33 
Table 4. KMO and Bartlett's test

\begin{tabular}{lll}
\hline \multicolumn{2}{l}{ Kaiser-Meyer-Olkin Measure of Sampling Adequacy } & .841 \\
\hline Bartlett's Test of Sphericity & Approx. Chi-Square & 5454.508 \\
& Df & 253 \\
& Sig. & 0.000 \\
\hline
\end{tabular}

Bartlett's test (Table 4) was used to test for the adequacy of the correlation matrix,among some variables. The observed correlation matrix of independent variables have a small off-diagonal coefficients. Bartlett's test of sphericity tests the hypothesis that the correlation matrix is an identity matrix, that is, all the diagonal terms are 1 and all off-diagonal terms are 0 . If the test value is large and the significance level is small $(<0.05)$, the hypothesis that the variables are independent can be rejected. In the present analysis, the Bartlett's test of sphericity yielded a value of 5454.508 and an associated level of significance smaller than 0.001 . Thus, the hypothesis that the correlation matrix is an identity matrix is rejected.

Table 5. Overall sum of variance explained

\begin{tabular}{|c|c|c|c|c|c|c|c|c|c|}
\hline \multirow[b]{3}{*}{ Component } & \multicolumn{3}{|c|}{ Initial Eigenvalues } & \multicolumn{3}{|c|}{$\begin{array}{l}\text { Sums of Squared Loadings } \\
\text { (Extraction) }\end{array}$} & \multicolumn{3}{|c|}{$\begin{array}{l}\text { Sums of Squared Loadings } \\
\text { (Rotation) }\end{array}$} \\
\hline & & & & & & & & & \\
\hline & Total & Variance & Cumulative $\%$ & Total & Variance & Cumulative \% & Total & Variance & Cumulative \% \\
\hline 1 & 5.938 & 25.816 & 25.816 & 5.938 & 25.816 & 25.816 & 3.753 & 16.318 & 16.318 \\
\hline 2 & 3.171 & 13.788 & 39.604 & 3.171 & 13.788 & 39.604 & 2.539 & 11.039 & 27.357 \\
\hline 3 & 1.960 & 8.522 & 48.126 & 1.960 & 8.522 & 48.126 & 2.312 & 10.051 & 37.408 \\
\hline 4 & 1.494 & 6.495 & 54.621 & 1.494 & 6.495 & 54.621 & 2.244 & 9.757 & 47.165 \\
\hline 5 & 1.201 & 5.220 & 59.841 & 1.201 & 5.220 & 59.841 & 2.196 & 9.548 & 56.713 \\
\hline 6 & 1.011 & 4.394 & 64.235 & 1.011 & 4.394 & 64.235 & 1.730 & 7.522 & 64.235 \\
\hline 7 & .964 & 4.190 & 68.425 & & & & & & \\
\hline 8 & .786 & 3.419 & 71.844 & & & & & & \\
\hline 9 & .702 & 3.054 & 74.898 & & & & & & \\
\hline 10 & .644 & 2.799 & 77.696 & & & & & & \\
\hline 11 & .602 & 2.618 & 80.314 & & & & & & \\
\hline 12 & .577 & 2.508 & 82.823 & & & & & & \\
\hline 13 & .501 & 2.178 & 85.001 & & & & & & \\
\hline 14 & .452 & 1.965 & 86.965 & & & & & & \\
\hline 15 & .428 & 1.861 & 88.826 & & & & & & \\
\hline 16 & .411 & 1.789 & 90.615 & & & & & & \\
\hline 17 & .373 & 1.623 & 92.238 & & & & & & \\
\hline 18 & .353 & 1.534 & 93.771 & & & & & & \\
\hline 19 & .346 & 1.506 & 95.277 & & & & & & \\
\hline 20 & .315 & 1.370 & 96.648 & & & & & & \\
\hline 21 & .275 & 1.195 & 97.842 & & & & & & \\
\hline 22 & .271 & 1.177 & 99.019 & & & & & & \\
\hline 23 & .226 & .981 & 100.000 & & & & & & \\
\hline
\end{tabular}

Extraction Method: Principal Component Analysis. 
Table 5 presents the number of common factors computed, the eigenvalues associated with these factors, the percentage of total variance accounted for by each factor, and the cumulative percentage of total variance accounted for by the factors. Although twenty-three (23) factors were computed, it is obvious that not all twelve factors will be useful in representing the list of twenty-three variables. In deciding how many factors to extract to represent the data, it is helpful to examine the eigenvalues associated with the factors. Using the criterion of retaining only factors with eigenvalues of 1 or greater, the first Six factors were retained for rotation. These six factors accounted for $25.82 \%, 13.78 \%, 8.52 \%, 6.50 \%, 5.22 \%$ and $4.39 \%$ of the total variance, respectively. That is, almost $64.24 \%$ of the total variance were attributable to these factors. The remaining seventeen factors together account for approximately $35.76 \%$ of the variance. Hence, a model with six factors was adequate to represent the data.

Table 6. Rotated Component of absolute value greater than or equal to 0.5 Matrix

\begin{tabular}{|c|c|c|c|c|c|c|}
\hline & \multicolumn{6}{|c|}{ Component } \\
\hline & 1 & 2 & 3 & 4 & 5 & 6 \\
\hline q6001: public meeting & .845 & & & & & \\
\hline q6002: meet leader & .742 & & & & & \\
\hline q6003: club & .711 & & & & & \\
\hline q6004: neighborhood & .841 & & & & & \\
\hline q6005: friends & & & & .783 & & \\
\hline q6006: in another home & & & & .732 & & \\
\hline q6007: coworkers & .653 & & & & & \\
\hline q6008: religious services & & & & .568 & & \\
\hline q6009: how often go out? & & & & .551 & & \\
\hline q6010: want to get out more? & & & & & .508 & \\
\hline q6011: why not? & & & & & & \\
\hline q6012: general trust & & & & & .724 & \\
\hline q6013: have someone to trust & & & & & .797 & \\
\hline q6014: neighbors & & & .660 & & & \\
\hline q6015: coworkers & & & .841 & & & \\
\hline q6016: strangers & & & .801 & & & \\
\hline q6017: safe at home & & & & & & .734 \\
\hline q6018: safe on street & & & & & & .761 \\
\hline q6019: victim & & & & & .637 & \\
\hline q6020: interest & & .766 & & & & \\
\hline q6021: voted & & .667 & & & & \\
\hline q6022: say in govt & & .797 & & & & \\
\hline q6023: express yourself freely & & .815 & & & & \\
\hline
\end{tabular}

Extraction Method: Principal Component Analysis. Rotation Method: Varimax with Kaiser Normalization.

The Rotated Component Matrix presents the factors after varimax rotation. The identification of what these factors represent was necessary to consider what items loaded on each of the factors. The clustering of items for each factor and their wording offer the best clue as to the meaning of that factor. Therefore, five items were loaded on Factor 1 and an inspection of these items clearly shows that, these items reflect a Community involvement (q6001: public meeting, q6002: meet leader, q6003: club, q6004: neighborhood and q6007: co-workers) 
Factor 2 contained items that clearly reflect the political participation in elections q6020: interest, q6021: voted, q6022: say in government, and q6023: express freely in government).

Factor 3 contained items three items reflecting neighborliness (q6014: neighbors, q6015: co-workers, q6016: strangers).

Factor 4, contain items reflecting socio-cultural involvement (q6005: friends, q6006: in other homes, q6008: religious services, q6009: how often go out)

Factor 5 consists q6010: want to get out, q6012: general trust, q6013: have Someone to trust and q6019: victim, (personal trust).

Factor 6 had two variables namely q6017: safety at home, and q6018: safety at street, representing a security.

\section{Discussion}

This study sought to examine the correlation among community, social and political issues relative to individual's response to a variety of health questions.

First, a study of a variety of health questions tf individual responses, were grouped into contrasting categories which indicate Community, Social and Political aspects of individual life.

The identifiable factors using the criterion of retaining only factors with eigenvalues of 1 or greater, the first six factors were retained for rotation. These factors accounted for $25.82 \%, 13.78 \%, 8.52 \%, 6.50 \%, 5.22 \%$ and $4.39 \%$ of the total variance, respectively. That is, almost $64.24 \%$ of the total variance are attributable to these six factors. The remaining seventeen factors together accounted for approximately $35.76 \%$ of the variance. Thus a model with six factors may be adequate to represent the data

Also, five items loaded on Factor reflect Community involvement (q6001: public meeting, q6002: meet leader, q6003: club, q6004: neighborhood and q6007: co-workers). Factor 2 contained items which clearly reflect political participation in elections (q6020: interest, q6021: voted, q6022: say in governance and q6023: express freely in government). Factor 3 contains three items classified as neighborhood (q6014: neighbors, q6015: co-workers, q6016: stragers). Factor 4, contain items reflecting socio-cultural involvement (q6005: friends, q6006: in other homes, q6008: religious services, q6009: how often go out). Factor 5, was classified as confidential ( q6010: want to get out, q6012: general trust, q6013: have Someone to trust and q6019: victim). Factor 6 had two variables representing security (q6017: safety at home, and q6018: safety on the street).

Finally, there was a significant association between Community, Social and Political varies with the individual responses to the health questions.

Groupings such as "political" and "socio-cultural" involvement in this study partly covered earlier groupings by Paul, Marie \& Monique (2010) who argued that the existence of the multifaceted constructs of social cohesion suggested by theory has been corroborated by empirical analysis of the EVS data (i.e. Social cohesion consists of components of formal and substantial relationships and political and social-cultural domains), which was consistent with the present study.

In conclusion, the present study did not take to account the effects of protestant and evangelical communities as suggested by Andrews (2011) that mainline Protestant communities enhance social cohesion in rural England, while evangelical communities did not. However, this study revealed that social cohesion is enhanced through six factors such as community, political, neighborliness, socio-cultural, confidence and security. This coincide with a model of social capital that recognizes structural and cognitive components (Harpham, Grant \& Thomas, 2002). The cognitive component, labeled 'social cohesion', was conceptualized as a collective community level characteristic measured by the levels of trust, norms of reciprocity and the formation of strong social bonds within the local social structure (Kawachi \& Berkman, 2000; Subramanian, Lochner \& Kawachi, 2003; Stafford, Bartley, Sacker \& Marmot, 2003). There was some evidence to suggest that this concept of community-level social cohesion was useful in investigating the determinants of general health status (Stafford, Bartley, Sacker \& Marmot, 2003; Subramanian, Kim \& Kawachi, 2002)

\section{Acknowledgment}

We are grateful to all respondents and interviewers who made the SAGE survey in Ghana possible. Financial support was provided by the US National Institute on Aging through Interagency Agreements (OGHA 04034785; YA1323-08-CN-0020; Y1-AG-1005-01) with the World Health Organization and a Research Project Grant (R01 AG034479- 64401A1). WHO contributed financial and human resources to SAGE Ghana. The Ministry of Health, Ghana, is supportive of SAGE. The University of Ghana's Department of Community Health contributed 
training facilities, data entry support, and storage of materials. The Ghana Statistical Office provided the sampling information for the sampling frame and updates.

\section{References}

Andrews, W. R. (2011). Religious communities, immigration, and social cohesion in rural areas: Evidence from England. Rural Sociology, 76(4), 535-561.

Aizlewood, A., \& Pendakur, R. (2005). Ethnicity and Social Capital in Canada. Canadian Ethnic Studies, xxxvii(2).

Becares, L., Stafford, M., Laurence, J., \& Nazroo, J. (2011). Composition, Concentration and Deprivation: Exploring their Association with Social Cohesion among Different Ethnic Groups in the UK. Urban Studies, $1-17$.

Chan, J., To, H., \& Chan, E. (2006). Reconsidering social cohesion: Developing a definition and analytical framework for empirical research, Social Indicators Research, 75, 273-302. http://dx.doi.org/10.1007/s11205-005-2118-1

Cassiers, T., \& Kesteloot, C. (2012). Socio-spatial Inequalities and Social Cohesion in European Cities. Urban Studies, 49(9), 1909-1924.

Fieldhouse, E., \& Cutts, D. (2010). Does diversity damage social capital? A comparative study of neighborhood diversity and social capital in the US and Britain. Canadian Journal of Political Science/Revue canadienne de science politique, 43(2), 289-318.

Green, A., Preston, J., \& Janmaat, G. (2006). Education, Equality and Social Cohesion. Palgrave, Basingstoke.

Harpham, T., Grant, E., \& Thomas, E. (2002). Measuring social capital within health surveys: Key issues. Health Policy Plan, 17, 106-111. http://dx.doi.org/10.1093/heapol/17.1.106

Hickman, M., Crowley, H., \& Mai, N. (2008). Immigration and social cohesion in the UK (p. 240). Water, Palgrave Macmillan.

Kawachi, I., \& Berkman, L. (2000). Social cohesion, social capital, and health. In I. Kawachi, \& L. Berkman (Eds.), Social Epidemiology (pp. 174-177). New York: Oxford University Press.

Lancee, B., \& Dronkers, J. (2011). Ethnic, religious and economic diversity in Dutch neighbourhoods: Explaining quality of contact with neighbours, trust in the neighbourhood and inter-ethnic trust. Journal of Ethnic and Migration Studies, 37(4), 597-618. http://dx.doi.org/10.1080/1369183X.2011.545277

Leigh, A. (2006). Trust, Inequality and Ethnic Heterogeneity. The Economic Record, 82, 268-280. http://dx.doi.org/10.1111/j.1475-4932.2006.00339.x

Letki, N. (2008). Does Diversity Erode Social Cohesion? Social Capital and Race in British Neighbourhoods. Political Studies, 56(1), 99-126. http://dx.doi.org/10.1111/j.1467-9248.2007.00692.x

Marschall, M., \& Stolle, D. (2004). Race and the city: Neighborhood context and the development of generalized trust. Political Behavior, 26, 125-154. http://dx.doi.org/10.1023/B:POBE.0000035960.73204.64

Osberg, L. (2003). The Economic Implications of Social Cohesion (p. 272). University of Toronto Press.

Marschall, M., \& Stolle, D. (2004). Race and the city: Neighborhood context and the development of generalized trust. Political Behavior, 26, 125-154. http://dx.doi.org/10.1023/B:POBE.0000035960.73204.64

Paul, D., Marie, V., \& Monique, B. (2010). Construct Validation and Application of a Common Measure of Social Cohesion in 33 European Countries. Social Indicators Research, 98(3), 451-473.

Pennant, R. (2005). Diversity, Trust and Community Participation in England. London: Home Office.

Putnam, R. D. (2007). E Pluribus Unum: Diversity and Community in the Twenty-first Century The 2006 Johan Skytte Prize Lecture. Scandinavian Political Studies, 30(2), 137-174. http://dx.doi.org/10.1111/j.1467-9477.2007.00176.x

Riva, M., Curtis, S., Gauvin, L., \& Fagg, J. (2009). Unravelling the extent of inequalities in health across urban and rural areas: evidence from a national sample in England. Social science medicine, 68(4), 654-663.

Soroka, S. N., Johnston, R., \& Banting, K. (2007). Ethnicity, trust, and the welfare state. In F. Kay, \& R. Johnston (Eds.), Diversity, Social Capital, and the Welfare State. Vancouver: University of British Columbia Press. 
Stafford, M., Bartley, M., Sacker, A., \& Marmot, M. (2003). Measuring the social environment: social cohesion and material deprivation in English and Scottish neighbourhoods. Env Plan A, 35, 1459-1475. http://dx.doi.org/10.1068/a35257

Sturgis, P., Brunton-Smith, I., Read, S., \& Allum, N. (2011). Does ethnic diversity erode trust? Putnam's 'hunkering-down' thesis reconsidered. British Journal of Political Science, 41(1), 57-82.

Subramanian, S. V., Kim, D. J., \& Kawachi, I. (2002). Social trust and self-rated health in US communities: A multilevel analysis. J Urban Health, 79, 521-534. http://dx.doi.org/10.1093/jurban/79.suppl_1.S21

Subramanian, S. V., Lochner, K. A., \& Kawachi, I. (2003). Neighborhood differences in social capital: A compositional artifact or a contextual construct? Health Place 9, 33-44. http://dx.doi.org/10.1016/S1353-8292(02)00028-X

Taylor, J., Twigg, L., \& Mohan, J. (2010). Exploring the links between population heterogeneity and perceptions of social cohesion in England. Ethnicity and Integration, 3, 269-287. http://dx.doi.org/10.1007/978-90-481-9103-1_13

\section{Copyrights}

Copyright for this article is retained by the author(s), with first publication rights granted to the journal.

This is an open-access article distributed under the terms and conditions of the Creative Commons Attribution license (http://creativecommons.org/licenses/by/3.0/). 